\title{
Observation of Vapor Wall Deposition in a Smog Chamber Using Size Evolution of Pure Organic Particles
}

\author{
Vikram Pratap ${ }^{1}$, S. Aditya Kiran ${ }^{1}$, Qijing Bian², Jeffrey R. Pierce ${ }^{2}$, Philip K. Hopke1, \\ Shunsuke Nakao ${ }^{*}$ \\ ${ }^{1}$ Department of Chemical and Biomolecular Engineering, Clarkson University, Potsdam, NY 13676, USA \\ ${ }^{2}$ Department of Atmospheric Science, Colorado State University, Fort Collins, CO 80523, USA
}

\begin{abstract}
Prior studies have shown that neglecting the vapor wall loss could lead to the underestimation of the secondary organic aerosol (SOA) yields in smog chamber experiments. The majority of the previous studies investigated vapor wall loss of a wide range of semi-volatile organic vapors at room temperatures using extensive chemical analysis. This study poses a question: Can vapor wall deposition in a smog chamber be observed only using physical measurements of aerosol properties? This study assesses the significance of vapor wall loss using only the size evolution of pure organic compound particles. To our knowledge, this technique is used for the first time in assessing the vapor wall loss of chemical species in chamber experiments. Dark experiments were conducted by injecting pure levoglucosan particles into an outdoor smog chamber at multiple ambient temperatures, ranging from $-10^{\circ} \mathrm{C}$ to $+15^{\circ} \mathrm{C}$. Peak diameter analysis revealed levoglucosan particles shrunk by $\sim 37 \%$ at $15^{\circ} \mathrm{C}$ and $\sim 20 \%$ at $10^{\circ} \mathrm{C}$ experiments, whereas no shrinkage was observed at temperatures below $0^{\circ} \mathrm{C}$ suggesting significant vapor wall loss of levoglucosan at warmer temperatures (> 10 ${ }^{\circ} \mathrm{C}$ ). Two-Moment Aerosol Sectional (TOMAS) and additional simple kinetic model simulations suggest that the effects of temperature on vapor wall loss can primarily be explained by the change in saturation vapor pressure of the organic compound and that the lack of apparent vapor wall loss of levoglucosan below $0^{\circ} \mathrm{C}$ was due to kinetics, i.e., slow evaporation relative to the chamber experiment timescales. The same approach can be applied to other organic species to expand the range of volatility relevant to chamber experiments.
\end{abstract}

Keywords: Organic aerosol; Teflon chamber; Vapor wall loss; Levoglucosan; Low temperature.

\section{INTRODUCTION}

Smog chambers are one of the widely-used experimental systems to study atmospheric chemistry (Akimoto et al., 1979; Finlayson-Pitts and Pitts, 1986). However, smog chambers induce biases to measurements due to their walls (FinlaysonPitts and Pitts, 1986). Early smog chamber studies on ozone formation observed various contamination effects due to sorption processes on the surfaces of chambers (Bufalini et $a l .$, 1977). Grosjean (1985) measured vapor wall-loss rates of several organic (toluene, pyruvic acid, ammonia, etc.) and inorganic $\left(\mathrm{SO}_{2}, \mathrm{O}_{3}, \mathrm{NO}_{\mathrm{x}}\right)$ gaseous species on the walls of an outdoor Teflon chamber in dark and sunlight conditions. Later, McMurry and Grosjean (1985) systematically investigated wall losses of particles and gases on Teflon walls. However, the effects of wall losses of semi-volatile compounds on SOA formation yield estimations were not well understood.

\footnotetext{
* Corresponding author.

Tel.: +1-315-268-4471; Fax: +1-315-268-6654

E-mail address: snakao@clarkson.edu
}

Over the last decade, the role of vapor wall loss in SOA formation have gained increasing attention. Kroll et al. (2007) reported that the SOA yields observed in a smog chamber were systematically lower when inorganic seed particles were not initially present. They hypothesized that the lack of inorganic seeds led to an increased fraction of semi-volatile SOA precursors being lost by continued oxidation and fragmentation and/or being lost to the chamber walls during the induction period between the onset of the reactions and subsequent particle formation. More recent studies (McVay et al., 2014; Zhang et al., 2014; Nah et al., 2017) have confirmed that increasing the seed aerosol surface area usually reduces the vapor wall loss and increases the SOA formation. High oxidant concentrations were also found to reduce the effects of vapor wall loss by enhancing the overall chemical oxidation rates relative to vapor wall loss (Nah et al., 2016). Previous studies generally agree that vapor wall loss is a reversible process that approaches equilibrium (Matsunaga and Ziemann, 2010; Yeh and Ziemann, 2015; Ye et al., 2016). Huang et al. (2018) modeled the rate of wall deposition for more than 90 compounds using a two-layer model that accounts for the rapid absorption into the Teflon surface layer and the slower absorption into the inner layer. 
The volatility of the organic vapor, expressed as the saturation concentration $C^{*}\left(\mu \mathrm{g} \mathrm{m}^{-3}\right)$, is one of the key parameters in the vapor wall loss. Previous studies of vapor wall loss in a smog chamber (Matsunaga and Ziemann, 2010; Krechmer et al., 2016; Isaacman-Vanwertz et al., 2018) suggested that semi-volatile organics with $C^{*}$ around $10^{1}-10^{5} \mu \mathrm{g} \mathrm{m}^{-3}$, are most susceptible to deposition to walls in typical smog chamber experiments. The saturation pressure strongly depends on the temperature as expressed by the Clausius-Clapeyron equation. At lower temperatures, saturation vapor pressures decrease and atmospheric chemical reactions generally slow down (Ziemann and Atkinson, 2012). Therefore, SOA formation may increase or decrease depending on the relative importance of reaction kinetics versus the phase partitioning. In general, the SOA yield was found to be higher at lower temperatures (Takekawa et al., 2003; Pathak et al., 2007; Warren et al., 2009). Therefore, it is likely that the impact of temperature on SOA yield is dominantly driven by the vapor pressure of the chemical system (reactants and products) being studied. The temperature may also significantly affect the SOA composition. Kristensen et al. (2017) compared the composition of SOA formed by $\alpha$-pinene ozonolysis at 258 and $293 \mathrm{~K}$ and showed that the amount of carboxylic acids and dimer esters were affected by temperature through changes in the saturation vapor pressure and reaction kinetics. A recent major field campaign conducted during winter in the Northeastern United States showed that the growth of organic aerosol observed in winter was unexpectedly similar to those observed in the summer (Shah et al., 2019). Thus, there is a need for further studies on SOA formation in low temperature conditions relevant to the winter atmosphere as well as in the free troposphere.

Despite the potential importance of temperature in SOA formation, studies on the effect of temperature on vapor wall loss are still limited. Zhang et al. (2015) and Ye et al. (2016) measured vapor wall loss of a range of chemicals with different saturation concentration $\left(C^{*}\right)$ and examined the effect of temperature between $22-45^{\circ} \mathrm{C}$ using advanced online mass spectrometer, i.e., aerosol mass spectrometer (AMS) and chemical ionization mass spectrometer (CIMS). Some recent studies conducted at low temperature $\left(2^{\circ} \mathrm{C}\right)$ have examined the impact of the vapor wall loss on SOA yield for wood smoke aerosol (Bertrand et al., 2018a, b). Bertrand et al. (2018a, b) studied the loss (and vapor wall loss) of levoglucosan and found that the loss of levoglucosan in chamber experiments is largely driven by the vapor wall loss rather than the chemical loss. Pratap et al. (2019) investigated levoglucosan decay in wood smoke aerosol through chamber experiments in a subzero to low temperature range $\left(-8^{\circ} \mathrm{C}\right.$ to $+10^{\circ} \mathrm{C}$ ) and found the vapor wall loss of levoglucosan was negligible at temperatures $<0^{\circ} \mathrm{C}$. The chemical losses were negligible owing to the higher organic aerosol loading.

Overall, the previous literature suggests vapor wall loss significantly reduces the apparent SOA formation yields determined in smog chamber experiments. All of the previous studies of vapor wall loss employed chemical measurements of semi-volatile vapors (e.g., CIMS) (Krechmer et al., 2016) or particles (e.g., AMS) (Ye et al., 2016). In contrast, this study presents a complementary technique to evaluate vapor wall loss only based on the size evolution of pure particles, using levoglucosan as an example. In a case with significant vapor wall loss, the particles are expected to shrink due to evaporation. Several studies utilized evolution of particle peak diameters to investigate isothermal evaporation of particles (Grieshop et al., 2007; Vaden et al., 2011; Yli-Juuti et al., 2017; Sato et al., 2018). Those studies tracked particle diameters to investigate evaporation kinetics, equilibration time-scales, and/or reversible gas-particle partitioning of SOA in dilution induced evaporation systems. To our knowledge, ours is the first study to use particle shrinkage (particle evaporation) to assess vapor wall loss, especially using pure particles. The experiment temperature range $(-10$ to $\left.15^{\circ} \mathrm{C}\right)$ enabled us to examine a range of volatility $(0.06-$ $3.2 \mu \mathrm{g} \mathrm{m}^{-3}$ ) of levoglucosan. Past studies suggest that saturation vapor pressure is likely the key parameter that determines the vapor wall loss. Therefore, this study hypothesizes that the temperature dependence of vapor wall loss can be modeled using the temperature dependence of the saturation vapor pressure. The experimental data were analyzed and compared with model results to assess the effect of temperature on vapor wall loss. The new approach enables users to 1) experimentally confirm whether vapor wall loss occurs at all in a given experimental condition and 2) assess whether current understanding of vapor wall loss can reasonably explain observations, based on aerosol size distribution measurements.

\section{MATERIALS AND METHODS}

\section{Experimental Setup}

All experiments were performed in an outdoor $6 \mathrm{~m}^{3}$ fluorinated ethylene propylene (FEP) Teflon smog chamber (Pratap et al., 2019). The outdoor setup allows us to use ambient low temperatures in winter $\left(<0^{\circ} \mathrm{C}\right)$ native to Potsdam, NY. Levoglucosan (99\%, Sigma-Aldrich) was used in the experiments. Two aerosol generation approaches were used in the experiments. The first technique is the well-known atomization where levoglucosan was dissolved in 18.2 $\mathrm{M} \Omega$ deionized water, atomized, and injected into the chamber. The second technique is homogeneous nucleation that produces particles with no water (Kuwata et al., 2013). Briefly, the setup consists of a glassware wrapped with heating tape. A small amount of levoglucosan was placed inside the glassware and heated to $205-210^{\circ} \mathrm{C}$, slightly above the melting point of levoglucosan (Booth et al., 2011). Clean compressed air was used as a carrier gas at a flow rate of 1-3 SLPM to continuously flush the system. High-temperature vapors nucleate to particles upon cooling and were injected into the chamber by the carrier gas.

The experiments were conducted by first filling the chamber with air and then injecting levoglucosan particles. Particle size distributions were monitored using a scanning mobility particle sizer (SMPS) that consists of a differential mobility analyzer (DMA, 3071A, TSI) and a condensation particle counter (CPC, 3010, TSI). The temperature and humidity of the contents of the chamber were measured using a humidity meter (HC2-S3, Rotronic). The ambient 
temperature was measured using a temperature logger (Digit-TLH, LabJack). The temperature of the sheath flow in the SMPS was recorded using a thermocouple (EI-1034, LabJack) to confirm there were no significant differences between the ambient and sheath air temperature. Before each experiment, the chamber was cleaned by photolyzing nitrous acid (HONO) and flushed 3-4 times with clean air to reach a target particle concentration below $1 \times 10^{-2} \mu \mathrm{g} \mathrm{m} \mathrm{m}^{-3}$. Nitrous acid used for cleaning the chamber was prepared by mixing $225 \mathrm{~mL}$ of $\mathrm{NaNO}_{2}(3 \mathrm{mmol})$ and $75 \mathrm{ml}$ of $\mathrm{H}_{2} \mathrm{SO}_{4}(10 \mathrm{mmol})$ in a conical flask (Taira and Kanda, 1990). The contents were heated to approximately $40^{\circ} \mathrm{C}$ while the generated HONO was simultaneously flushed and injected into the chamber through a carrier gas via a diffusion dryer.

\section{Model}

The Two-Moment Aerosol Sectional (TOMAS) microphysics model

The TOMAS microphysics model coupled to the organic volatility basis set was used in this work, and is based on Bian et al. (2015). The model accounts for various physical processes: coagulation, condensation/evaporation, and particle/vapor wall loss. A brief description is provided here.

The loss of particles to the walls of the chamber is assumed to be of the first order and depends on the size of the particles:

$$
\left(\frac{\partial n\left(d_{p}, t\right)}{\partial t}\right)=-k_{p}\left(d_{p}, t\right) n\left(d_{p}, t\right)
$$

$k_{p}$ is the particle wall loss rate constant which depends on the particle diameter $\left(d_{p}\right)$, time, shape and size of the chamber, turbulence in the chamber, number of charges on the particle and the electric field on the bag. $k_{p}$ is determined by applying Aerosol Parameter Estimation (APE) model (Pierce et al., 2008) on SMPS measurements. APE simultaneously estimates size-dependent particle-wall-loss rates and condensation/evaporation rates (though it does not estimate what is driving condensation and evaporation rates).

Vapor wall deposition is represented by a first order deposition coefficient $k_{\text {wall,on }}$ (McMurry and Grosjean, 1985),

$$
k_{\text {wall }, \text { on }}=\frac{A}{V} \frac{\frac{\alpha_{\text {wall }} \bar{C}}{4}}{1.0+\frac{\pi}{2}\left[\frac{\alpha_{\text {wall }} \bar{C}}{4\left(k_{e} D_{i}\right)^{0.5}}\right]}
$$

where $A / V$ is the surface area-to-volume ratio of the chamber, $\alpha_{\text {wall }}$ is the accommodation coefficient for the vapor species on the wall, assumed to be $10^{-5}$ based on the value used in Matsunaga and Ziemann (2010) and Bian et al. (2015). In the sensitivity tests performed by Bian et al. (2015), the $\alpha_{\text {wall }}$ value of $10^{-5}$ generally performed better than (1) the volatility-dependent $\alpha_{\text {wall }}$ with a range from $10^{-8}$ to $10^{-6}$ as proposed by Zhang et al. (2015) and (2) constant values of $10^{-4}, 10^{-2}$, and $1 . \bar{c}$ is the mean thermal speed of the molecules at the ambient temperature, $D_{i}$ is the gas phase diffusivity of the condensing species and $k_{e}$ is the coefficient of eddy diffusion that characterizes the degree of mixing in the chamber. In this study, the APE model was used to estimate $k_{e}$ for the TOMAS simulations (Pierce et al., 2008) ( $k_{e}$ is the rate of turbulent mixing from the bulk of the chamber to near the walls, and its value is the same for both particles and vapors). In case of simple kinetic model (sections 2.2.2 and 3.3), the chamber volume-based parameterization recommended by Krechmer et al. (2016) was used to estimate $k_{e}\left(=0.004+\left(5.6 \times 10^{-3}\right)\left(\mathrm{V}\left[\mathrm{m}^{3}\right]\right)^{0.74} \mathrm{~s}^{-1}\right)$.

The interaction of vapors with the wall is assumed to be reversible. The rate coefficient of desorption from the wall is given by:

$k_{\text {wall }, \text { off }}=\frac{k_{\text {wall }, o n}}{K_{w} C_{w}}=k_{\text {wall }, o n}\left(\frac{C_{i}^{*} M_{w} \gamma_{w}}{C_{w} M_{p} \gamma_{p}}\right)$

where $k_{\text {wall,off }}$ is the rate coefficient of desorption, $K_{w}=$ $R T / M_{w} \gamma_{w} P^{o}$ is the gas wall partitioning coefficient, $C_{w}$ is the equivalent wall mass concentration, $M_{p}$ and $M_{w}$ are the average molecular weight of the chemical species in the particle phase and the Teflon film $\left(M_{w}\right.$ is assumed to be 250 $\mathrm{g} \mathrm{mol}{ }^{-1}$ ) (Krechmer et al., 2016), $C^{*}=M_{p} \gamma_{p} P^{o} / R T$ is the saturation concentration of the chemical species, $R$ is the universal gas constant, $T$ is the temperature, and $P^{o}$ is the liquid vapor pressure of the compound at the experimental temperature. $\gamma_{w}$ is the activity coefficient of the compound absorbed into the Teflon film. The temperature, $T$, used in the model calculations, is the average temperature during the course of the experiment (Table S1) to simplify simulations.

\section{A Simple Kinetic Model}

In order to obtain insights into the dependence of vapor wall loss on a wide range of experimental conditions, a simple kinetic model was developed based on previous studies (Matsunaga and Ziemann, 2010; La et al., 2016). The simple model is easy to run/modify, allows easier sensitivity analyses, and serves a tool to researchers who may not have access to comprehensive aerosol microphysics models like the TOMAS model. The simple model employs the following four first-order rate coefficients to describe the gas-particlewall partitioning: (1) the partitioning of the gas-phase organics to the particle phase $\left(k_{g p}\right)$, (2) partitioning of the particlephase organics to the gas phase $\left(k_{p g}\right)$, (3) partitioning of the gas-phase organics to the walls $\left(k_{g w}=k_{\text {wall,on }}\right.$ in Eq. (2)), and (4) partitioning of the organics from the walls to the gas phase $\left(k_{w g}=k_{\text {wall,off }}\right.$ in Eq. (3)). $k_{g p}$ and $k_{p g}$ are calculated as (Matsunaga et al., 2010)

$$
\begin{aligned}
& k_{g p}=2 \pi d_{p} N D_{g}=\frac{12 D_{g} C_{p}}{\rho_{p} d_{p}^{2}} \\
& k_{p g}=\frac{k_{g p} C_{i, e q}^{g}}{C_{i, e q}^{p}}=\frac{k_{g p} C_{i}^{*}}{C_{p}}=\frac{12 D_{g} C_{i}^{*}}{\rho_{p} d_{p}^{2}}
\end{aligned}
$$

where $d_{p}$ is the particle diameter, $N$ is the number of particles, 
$D_{g}$ is the diffusion coefficient of the compound in the gasphase, $C_{p}$ is the mass concentration of the compound in the particle phase, $\rho_{p}$ is the density of the compound in the particle phase, $C_{i, e q}^{g}$ and $C_{i, e q}^{p}$ are the equilibrium concentrations of the organic species in the gas and the particle-phase respectively. By definition, the saturation concentration $C_{i}^{*}$ is an inverse of the gas-particle equilibrium constant, and thus $C_{i}^{*}=\frac{C_{i, e q}^{g} C_{p}}{C_{i, e q}^{p}}$ (Donahue et al., 2006). The expressions for $k_{g p}$ and $k_{p g}$ neglect the Fuchs correction factor for simplicity, consistent with the methodology of (Matsunaga and Ziemann, 2010). The evolution of the organic concentrations in the gas $\left(C_{i}^{g}\right)$, the particle $\left(C_{i}^{p}\right)$, and the wall $\left(C_{i}^{w}\right)$ phases are described by the following set of ordinary differential equations (ODEs):

$$
\begin{aligned}
& \frac{d C_{i}^{g}}{d t}=-k_{g p} C_{i}^{g}+k_{p g} C_{i}^{p}-k_{g w} C_{i}^{g}+k_{w g} C_{i}^{w} \\
& \frac{d C_{i}^{p}}{d t}=k_{g p} C_{i}^{g}-k_{p g} C_{i}^{p} \\
& \frac{d C_{i}^{w}}{d t}=k_{g w} C_{i}^{g}-k_{w g} C_{i}^{w}
\end{aligned}
$$

This study uses a stiff ODE solver in MATLAB, "ode15s", for solving the system of ODEs. The MATLAB codes are included in the supplementary material. The equilibrium wall concentration $\left(C_{i, e q}^{w}\right.$ ) can be calculated by setting Eq. (8) to zero:

$$
\begin{aligned}
C_{i, e q}^{w} & =\frac{k_{g w}}{k_{w g}} C_{i, e q}^{g}=C_{w} \frac{M_{p} \gamma_{p}}{M_{w} \gamma_{w}} \frac{C_{i, e q}^{g}}{C_{i}^{*}}=C_{w} \frac{M_{p} \gamma_{p}}{M_{w} \gamma_{w}} \frac{C_{i, e q}^{p}}{C_{p}} \\
& =C_{w} \frac{M_{p} \gamma_{p}}{M_{w} \gamma_{w}} x_{m . i}
\end{aligned}
$$

where $x_{m, i}$ is the mass fraction of species $i$ in the particle phase. When pure particles are considered (as in this study's experiments), $C_{i}^{p}=C_{p}$ and $d_{p}=\left(\frac{6 C_{p}}{\pi \rho_{p} N}\right)^{3}$ assuming spherical particles.

The model accounts for the temperature dependence of $C^{*}, D_{g}$, and $c$. The temperature dependence of the saturation concentration can be estimated using the Clausius-Clapeyron equation:

$$
C_{i}^{*}(T)=C_{i, 298}^{*}\left(\frac{298}{T}\right) \exp \left[\frac{\Delta H^{\text {vap }}}{R}\left(\frac{1}{298}-\frac{1}{T}\right)\right]
$$

where $\Delta H^{v a p}$ is the enthalpy of evaporation with $\Delta H^{v a p}=$ $101 \mathrm{~kJ} \mathrm{~mol}^{-1}$ and $C_{i, 298}^{*}=13.0 \mu \mathrm{g} \mathrm{m}^{-3}$ for levoglucosan (May et al., 2012). The temperature dependence of $D_{g}$ is calculated as

$$
D_{g, T}=D_{g, 298}\left(\frac{T}{298}\right)^{\mu}
$$

where $\mu$ is assumed to be 1.75 (Riipinen et al., 2010). The temperature dependence of $c^{-}$is from the kinetic theory of gases: $\bar{c}=\sqrt{\frac{8 R T}{\pi M}}$. The overall temperature dependence is dominated by $C^{*}$. For instance, when temperature decreases from $25^{\circ} \mathrm{C}$ to $0^{\circ} \mathrm{C}, C^{*}$ of levoglucosan decreases by nearly a factor of 40 , whereas $D_{g}$ and $\bar{c}$ decrease by only $17 \%$ and $4 \%$, respectively.

Krechmer et al. (2016) presented a correlation between the equilibrium vapor wall loss coefficient $C_{w}$ and $C^{*}$ as

$C_{w}=\left\{\begin{array}{ccc}10-30 \times 10^{3} \mu \mathrm{g} \mathrm{m}^{-3} & \text { for } & c^{*}>10^{4} \\ 16\left(c^{*}\right)^{0.6} \mu \mathrm{g} \mathrm{m}^{-3} & \text { for } & 1<c^{*}<10^{4} \\ 16 \mu \mathrm{g} \mathrm{m}^{-3} & \text { for } & c^{*}<1\end{array}\right.$

where $c^{*}$ is the saturation concentration based on the wall molecular weight and activity coefficient, i.e., $c^{*}=$ $\frac{M_{w} \gamma_{w} p^{o}}{R T}=\frac{M_{w} \gamma_{w}}{M_{p} \gamma_{p}} C^{*}$

\section{RESULTS AND DISCUSSION}

\section{Experimental Results}

A summary of the experimental conditions of the study is presented in Table S1. In almost all experiments, bimodal particle size distributions were observed (Fig. S1). The small-mode peak at $\sim 20-40 \mathrm{~nm}$ was likely due to either lowvolatile impurities or crystalline levoglucosan particles (Anisimova et al., 2001). Anisimova et al. (2001) observed bimodal particle size distribution of homogeneously nucleated glycerin particles and concluded that the difference in sticking probabilities of vapor molecules colliding with different phase surfaces resulted in small crystalline particles and larger liquid droplets. Crystalline levoglucosan is generally significantly less volatile than sub-cooled levoglucosan (Table S2). Experiments 1,2, and 4 were performed at lowtemperatures $\left(-3^{\circ} \mathrm{C},-10^{\circ} \mathrm{C}\right.$ and $-8^{\circ} \mathrm{C}$ respectively), and therefore, the small-mode particles were not expected to shrink (evaporate) and indeed did not shrink during the course of the experiment (Fig. S2(a)). The peak diameters observed for exp. 2 and 4 remain unchanged during the experiment in Fig. S2(a). The minor increase in the peak diameter initially was likely due to the uncertainties in sizedependent particle wall-loss corrections. The outcomes were also supported by TOMAS simulation results shown in Fig. S2(b) for exp. 4. TOMAS was able to simulate the experiment well accounting for the temperature dependence of levoglucosan's volatility. Experiment 5 was a relatively warm experiment $\left(10^{\circ} \mathrm{C}\right)$ with a clear bi-modal distribution (Fig. S1). The calculated peak diameters (small-mode and 
large-mode) in exp. 5 are shown in Fig. S2(c). It can be seen that the large-mode particles shrunk by $20 \%$ while the smallmode peak diameter remained unchanged even though small-mode would have disappeared due to evaporation if it was entirely levoglucosan. This result suggests that the small-mode particles were low/non-volatile. Since exp. 5 used an atomizer unlike exp. 2 and 4 that used homogeneous nucleation $(\mathrm{HN})$, it is possible that trace amount of lowvolatile impurities in deionized water resulted in small lowvolatile particles.

Since we could not definitively determine the nature and composition of small-mode peak particles (impurity, crystalline or a mix of both impurity and levoglucosan crystalline structure), we focused our analysis on the large-peak (> $40 \mathrm{~nm}$ ) that was more consistent between experiments, and likely not affected by impurity or the crystalline phase. Although the number fraction of the large mode was relatively small (Fig. S1(a)), the volume fraction of the large mode was significant (Fig. S1(b)) to carry out the analysis. We also note that the choice of the smaller mode vs. larger mode does not fundamentally change the conclusions of this study except for experiment 5 since experiment 2 and 4 were both at low temperatures $\left(-10\right.$ and $-8^{\circ} \mathrm{C}$, respectively), and therefore levoglucosan is expected to be low-volatile. The peak diameter analysis was performed on the number distribution of the particles instead of volume distribution. In general, the volume distribution is skewed towards larger particles that have smaller number concentrations. Therefore, the peak diameters of volume distribution have greater experimental noise (Fig. S1(b)). In addition, the peak diameter values extracted from the volume distribution may not be as sensitive to vapor wall-loss as that from number distribution. For example, for the same amount of evaporation, larger particles (volume-based peak value) will have relatively lower reduction in diameter compared to smaller particles (number-based peak value).

We investigated the effect of temperature on the vapor wall loss by observing the time-evolution of the particle peak diameters of the large-mode determined by bimodal log-normal curve fits to the size distribution data. It should be noted that log-normal curve fits were applied to particle number-size distribution after applying the size-dependent particle wall-loss correction based on the rate coefficients characterized in a separate experiment using ammonium sulfate. When there is significant vapor wall loss of levoglucosan, the particles are expected to shrink during the course of the experiment. Fig. 1 shows the time-evolution of the peak diameter of all experiments. It can be seen that more evaporation was observed in experiments at warmer temperatures. The peak diameter in experiment $3\left(15^{\circ} \mathrm{C}\right)$ reduced by $37 \%$ from $73 \mathrm{~nm}$ to $46 \mathrm{~nm}$, a moderate reduction of $20 \%$ in experiment $5\left(10^{\circ} \mathrm{C}\right)$, and no change in experiments 1,2 and 4 (below $0^{\circ} \mathrm{C}$ ). The results clearly indicate the evaporative loss of levoglucosan from the aerosol to walls at warmer temperatures. The most likely reason for no evaporative loss of levoglucosan from particles at temperatures below $0^{\circ} \mathrm{C}$ is kinetic limitation driven by extremely low vapor pressure of $\sim 0.32 \mu \mathrm{g} \mathrm{m}^{-3}$ that is an order of magnitude lower than the same at $15^{\circ} \mathrm{C}\left(C^{*} \sim 3.2 \mu \mathrm{g} \mathrm{m}^{-3}\right)$. This is further

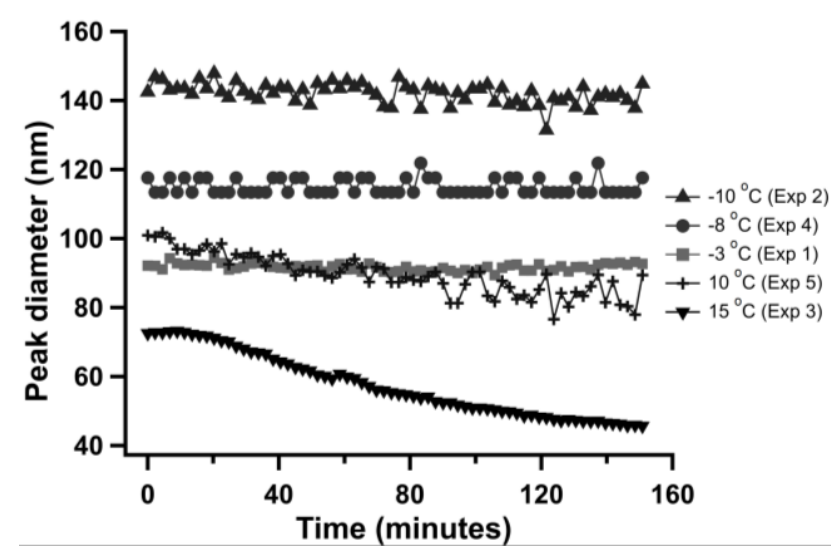

Fig. 1. Peak diameters of the log-normal distribution of $d N / d \log d_{p}$ of different experiments.

discussed in detail in subsequent sections. Overall, the results suggest no apparent vapor wall loss of levoglucosan at $\mathrm{T}<0^{\circ} \mathrm{C}$.

\section{The TOMAS Model}

Next, the experimental results were compared against the model simulations using the TOMAS microphysics model that accounts for particle microphysics (coagulation, evaporation, and particle wall loss) as well as vapor wall loss as described in section 2.2.1. The model takes the initial particle size distribution from the experiment and other experimental conditions (for example, temperature) to simulate the evolution of the particle size distribution. Results from the model are shown in Fig. 2. Fig. 2(a) shows the decay in the mass of levoglucosan for experiment 4 performed at $-8^{\circ} \mathrm{C}$. The model results indicate no vapor wall loss, with only $0.2 \%$ of the aerosol mass lost after 2.5 hours of the experiment. There is some disparity between the model and experiment data towards the later part of the experiment. This disparity is likely due to the sensitivity of the model towards size dependent particle wall-loss rates, which are themselves uncertain. On the other hand, Fig. 2(b) shows a similar plot for experiment 3 conducted at $15^{\circ} \mathrm{C}$. In this case, there was a significant amount of vapor wall loss $(\sim 22 \%$ of aerosol mass) and the drop in the total mass concentration of the levoglucosan could be accounted only after incorporating vapor wall loss in the model.

To estimate the peak diameter from the TOMAS model output, the simulated particle size distribution from TOMAS model was fitted to a bi-modal log-normal distribution. The extracted peak diameters (large-mode) from the log-normal distribution are plotted in Fig. 3. The evolution in the experimental particle peak diameters in Experiment 3 and 4 are compared with those of the TOMAS model and the simple kinetic model. The simple kinetic model (described in section 2.2.2) assumes that the particle mass concentrations equal the mid-point values $\left(C_{p}=22.5\right.$ and $5 \mu \mathrm{g} \mathrm{m}^{-3}$ in experiment 3 and 4 , respectively) assuming that the overestimation of evaporation in the early part of the experiments (due to a lower $C_{p}$ value) would mostly cancel out with the under-estimation of evaporation in the latter part of the experiment (due to a higher $C_{p}$ value). The warmer temperature 

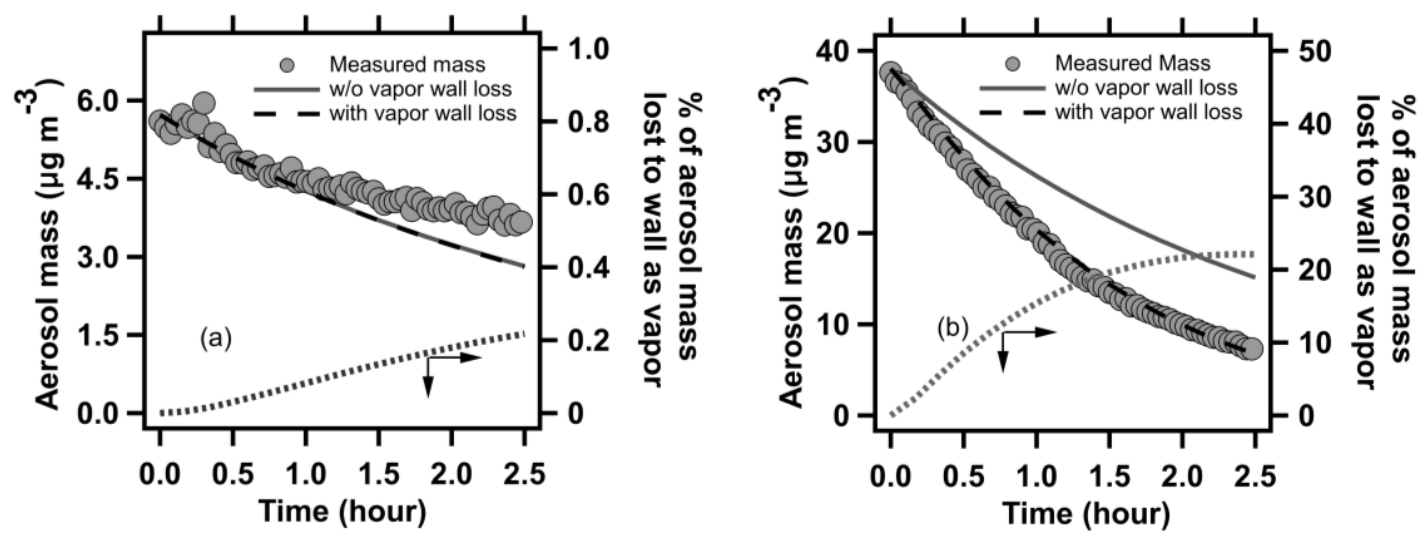

Fig. 2. Total mass concentration of levoglucosan and corresponding simulations by the TOMAS model with and without vapor wall losses for (a) experiment $4\left(-8^{\circ} \mathrm{C}\right)\left(k_{e}=0.08 \mathrm{~s}^{-1}\right)$ and (b) experiment $3\left(15^{\circ} \mathrm{C}\right)\left(k_{e}=0.38 \mathrm{~s}^{-1}\right)$. Dotted line shows the percentage of aerosol mass lost to wall as vapor in the corresponding model experiment.

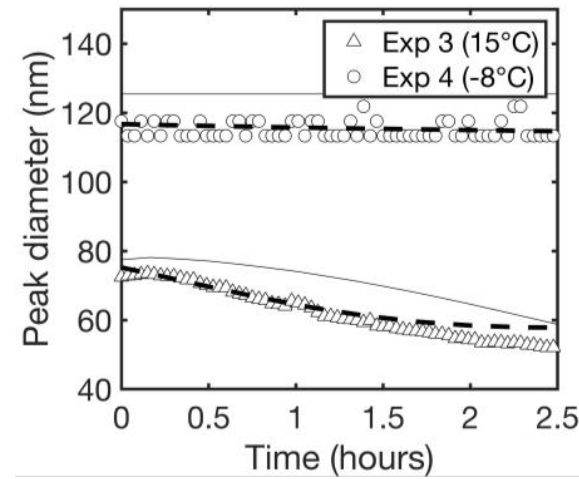

Fig. 3. Comparison between experimentally observed trends of the peak diameters (symbols) of experiments $3\left(15^{\circ} \mathrm{C}\right)$ and $4\left(-8^{\circ} \mathrm{C}\right)$ and the corresponding model simulations by TOMAS (solid lines) and the simple kinetic model (dashed lines).

(Exp. 3: $15^{\circ} \mathrm{C}$ ) resulted in significant shrinkage of the particles due to vapor wall loss whereas no significant shrinkage was observed at the lower temperature (Exp. 4: $-8^{\circ} \mathrm{C}$ ). The predicted trends from TOMAS and the simple kinetic model of particle diameters are reasonably consistent with the experimental results, again suggesting that diameters of pure particles with known volatility can be a useful indicator of vapor wall loss. The difference in the peak diameter at time $t=0$ in TOMAS model is due to the residual from the methodology adopted in extracting the peak diameter from TOMAS. The slight gap does not affect the overall observation. The simple kinetic model is further applied to a wider range of conditions in the following section to understand the impact of various parameters on vapor wall loss. The sensitivity of the simulations results to reference volatilities, $C_{i, 298}^{*}$, and the heat of vaporization is evaluated in the supplementary information (Text S1) (May et al., 2012; Booth et al., 2011; Oja and Suuberg, 1999) and compared to experimentally determined peak diameters. The parameters $\left(C_{i, 298}^{*}\right.$ and the heat of vaporization) determined in May et al. (2012) appear to agree best with our experimental results. An averaged value of the temperature over the entire period of the experiment was used for easier model simulations. Therefore, we also evaluated the sensitivity of results to the temperature (average temperature versus time-series), and found minor discrepancy in estimated peak diameters (Fig. S6).

\section{Simple Kinetic Model}

Fig. 4 shows example results of the kinetic model assuming pure levoglucosan particles with initial $C_{p}=50 \mu \mathrm{g} \mathrm{m}^{-3}$ and $d_{p}=100 \mathrm{~nm}$. The duration is assumed to be 30 hours to illustrate the attainment of equilibrium conditions although it is not attainable in a typical smog chamber experiment. The results are qualitatively consistent with the experimental observations where significant particle shrinkage was observed only at higher temperature experiments (Fig. 1). Fig. 4 shows that at lower temperatures the equilibrium wall concentrations of levoglucosan decreases (dashed lines in Figs. 4(a), 4(c), and 4(e)) because of lower $C^{*}$ (and hence lower $C_{w}$ ). This change is a thermodynamic effect. However, more importantly, as the temperature goes down, the system takes much longer to approach the equilibrium vapor wall concentrations. These simulations suggest that the kinetics of vapor wall deposition play a dominant role in determining the apparent evaporation of levoglucosan particle in typical duration of chamber experiments (e.g., $<10$ hours) even at $15^{\circ} \mathrm{C}$. Note, as per the eqn. (12), the $C^{*}$ of levoglucosan at $5^{\circ} \mathrm{C}$ and $-5^{\circ} \mathrm{C}$ are 0.7 and $0.1 \mu \mathrm{g} \mathrm{m}^{-3}$ respectively, and hence the value of $C_{w}=16 \mu \mathrm{g} \mathrm{m}^{-3}$ applies to both cases (Krechmer et al., 2016). We further evaluated whether gas-particle partitioning or gas-wall partitioning is the rate-limiting step. Matsunaga and Ziemann (2010) calculated the time constants for reaching gas-particle and gas-wall partitioning equilibrium as

$$
\begin{gathered}
\tau_{g p}=\frac{1}{k_{g p}+k_{p g}} \\
\tau_{g w}=\frac{1}{k_{g w}+k_{w g}}
\end{gathered}
$$



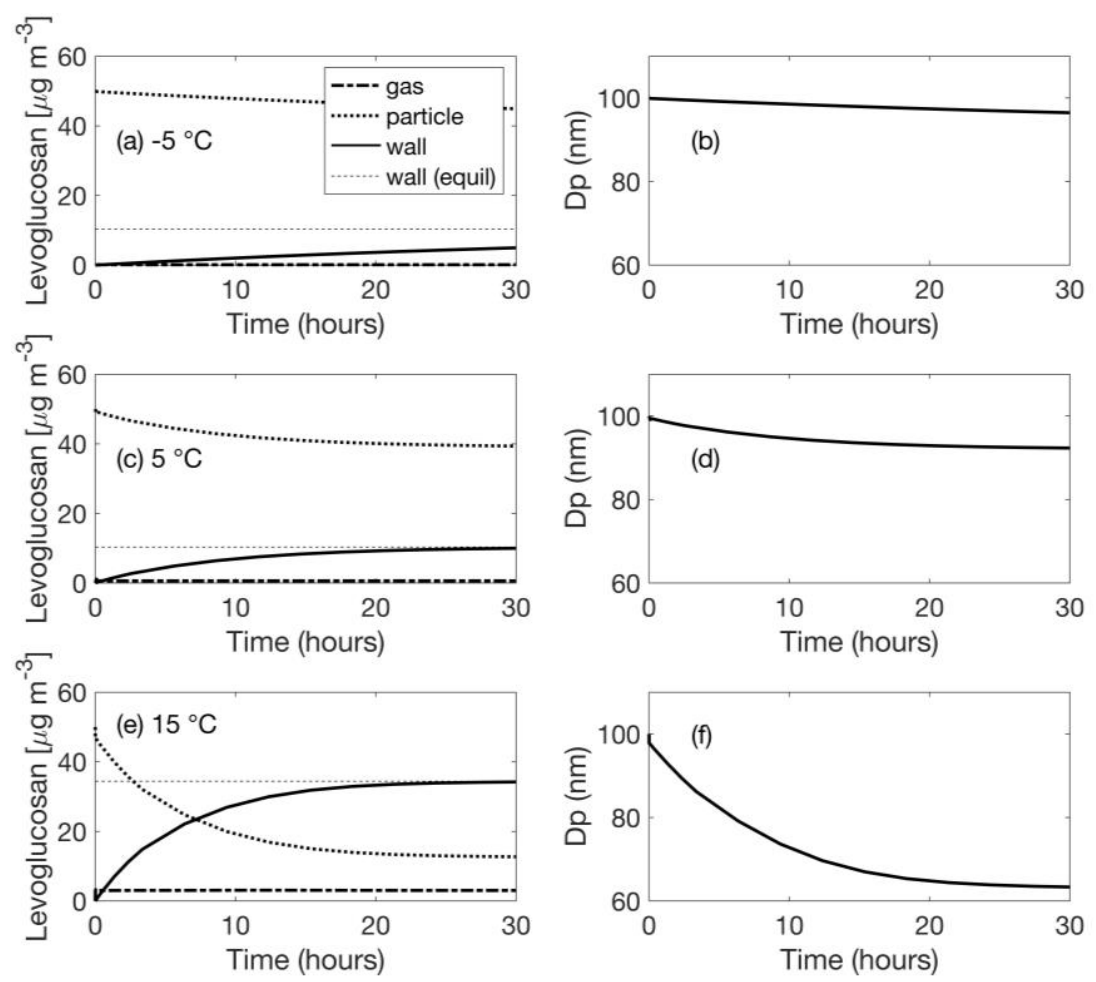

Fig. 4. Simulated concentrations of levoglucosan in the gas-phase, particle-phase, and on the wall at $(\mathrm{a})-5^{\circ} \mathrm{C}\left(C^{*}=0.1 \mu \mathrm{g} \mathrm{m} \mathrm{m}^{-3}\right)$, (b) $5^{\circ} \mathrm{C}\left(C^{*}=0.7 \mu \mathrm{g} \mathrm{m}^{-3}\right)$, and (c) $15^{\circ} \mathrm{C}\left(C^{*}=3.1 \mu \mathrm{g} \mathrm{m}^{-3}\right)$, and corresponding particle diameters (b, d, and f). The equilibrium wall concentrations (dashed lines in a, c, and e) are calculated using Eq. (9).

Under the conditions for the results shown in Fig. 4, the time constants are calculated to be $\tau_{g p} \approx 0.1$ and $\tau_{g w} \approx 30$ minutes, indicating that gas-wall partition was the ratelimiting step under these conditions. This result is consistent with the rapid adjustment of gas-phase levoglucosan concentration near time zero in Fig. 4(e) and the nearly constant gas-phase levoglucosan concentration (dashed line) throughout the simulation.

When interpreting the diameter evolutions, it is important to recognize that a higher mass concentration of particles would result in lesser extent of particle shrinkage because a relatively smaller fraction of particle mass is lost by vapor wall loss. Fig. 5 illustrates the dependence of levoglucosan particle shrinkage on temperature and total levoglucosan concentrations. Corresponding concentrations on the wall, and in the gas and particle phases are shown in Fig. S7 in the supplementary material (Text S2). Despite the simplicity of the model, the estimated diameter changes in Fig. 5 are fairly consistent with experimental observations shown in Fig. 1 where significant particle shrinkage was observed only in experiment $3\left(15^{\circ} \mathrm{C}\right)$ and $5\left(10^{\circ} \mathrm{C}\right)$. Fig. 5 suggests that the shrinkage of pure particles can be used as a tool to assess the significance of vapor wall loss over around $10^{-1}<\mathrm{C}^{*}<$ $10^{1} \mu \mathrm{g} \mathrm{m}^{-3}$ when appropriate particle mass concentrations were used (e.g., corresponding to the region where diameter ratio is < 0.95). When coupled with the simple kinetic model, one can confirm that current understandings of vapor wall loss reasonably explain the observations only based on aerosol size distribution measurements (Fig. 3).

\section{Discussion}

This study assumed that the effects of temperature on gasparticle-wall partitioning are primarily driven by $C^{*}$. The assumption was generally consistent with observed trends of levoglucosan particles with changing temperature. However, other factors not considered in this study may play a role. For example, this study assumes that the parameterization of $C_{w}$ determined at room temperature (Eq. (12)) is applicable to colder conditions. However, the properties of Teflon may change at lower temperatures and, hence, the parameterization of $C_{w}$ may also be temperature dependent. This work used levoglucosan as a test compound and examines a range of volatility $\left(0.06-3.2 \mu \mathrm{g} \mathrm{m}^{-3}\right)$ by varying the temperature. A range of compounds with a broader volatility would be desired in a future work. Nevertheless, the study demonstrates the approach of using particle shrinkage as a means to assess vapor wall loss.

It should be noted that the focus of this study is to demonstrate observation of vapor wall deposition in a smog chamber only using physical measurements of aerosol. The implication of vapor wall deposition on the interpretation of experimental SOA yields in smog chamber experiments is beyond the scope of this study, and we suggest interested readers refer to other recent studies (e.g., Roldin et al., 2014; Trump et al., 2016; Huang et al., 2018; Isaacman-Vanwertz et al., 2018). This study operated the smog chamber as a batch system, whereas some studies operate smog chambers as continuous mixing flow reactors (CMFR) (Krechmer et al., 2020). We expect that the significance of vapor wall deposition would depend on the time constants for gas-particle 


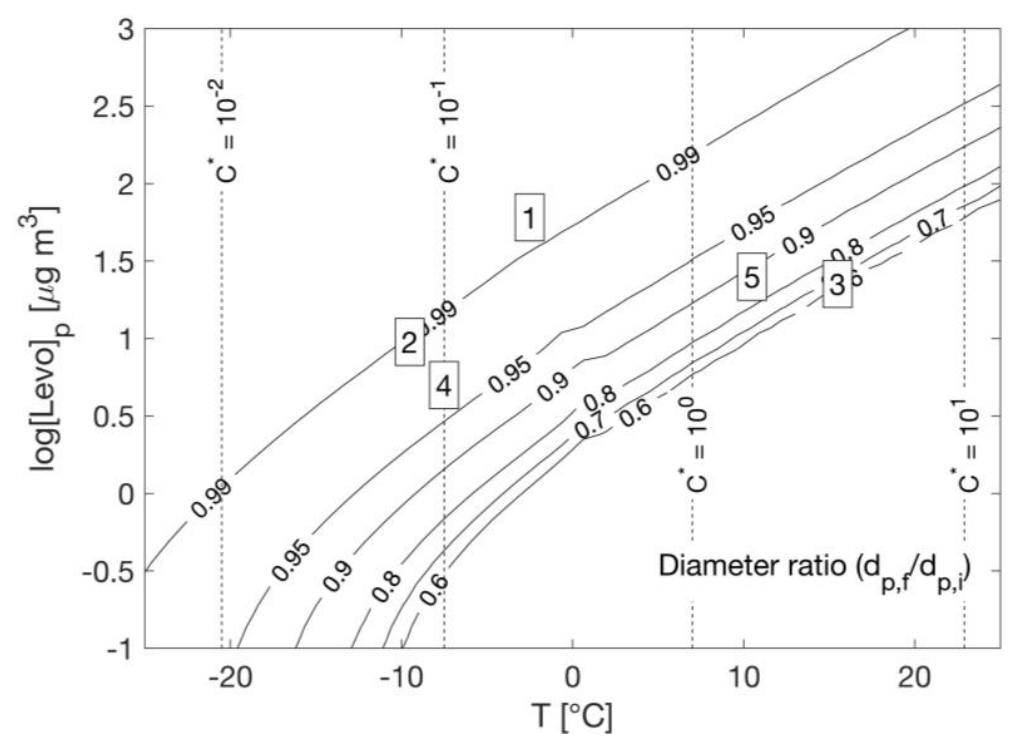

Fig. 5. Simulated shrinkage of levoglucosan particles expressed as the ratio of the final diameter $\left(d_{p, f}\right)$ to the initial diameter $\left(d_{p, i}\right)$ as a function of the levoglucosan particle concentrations ([Levo $\left.]_{p}\right)$ and temperature. The calculation assumes $d_{p}=100 \mathrm{~nm}$ and 2.5 hours of elapsed time. The numbers in boxes are the experiment numbers at corresponding conditions.

partitioning ( $\tau_{g p}$, Eq. $\left.(13)\right)$, gas-wall partitioning $\left(\tau_{g w}\right.$, Eq. $\left.(14)\right)$ and the residence time distribution in the CMFR chamber. Further studies are needed in evaluation of the implication of vapor wall deposition in CMFR-type chambers.

\section{CONCLUSIONS}

This study developed a relatively simple approach to observe vapor wall loss in a smog chamber using only pure particles size distributions under different temperatures. The evolution of the levoglucosan particle size indicated that levoglucosan vapor wall loss was significant above around $10^{\circ} \mathrm{C}$ whereas negligible below around $0^{\circ} \mathrm{C}$ under the experimental conditions used in this study. The model simulations suggested that the lack of apparent vapor wall loss in colder conditions was due to the slow evaporation of levoglucosan despite significant vapor wall loss predicted at equilibrium. In addition to temperature, the mass concentration of particle was found to be an important parameter for quantitative interpretation of the particle shrinkage due to vapor wall loss. A lower mass concentration would result in a higher sensitivity of the pure particle diameter to vapor wall loss. The TOMAS model was able to reasonably estimate the vapor wall loss occurred in the experiments. In principle, the experimental approach should be applicable to other pure species with different volatility, which would expand the range of volatility to be examined. This study confirmed that the volatility dependence on temperature is a major factor in how temperature impacts vapor wall loss in a smog chamber. However, it does not rule out other mechanisms for temperature dependence of vapor wall loss such as temperature-dependent wall properties. The approach presented in this study allows assessment of vapor wall loss in a smog chamber even when direct chemical analysis of semi-volatile organic vapors is not feasible.

\section{ACKNOWLEDGEMENT}

We acknowledge funding support from New York State Energy Research and Development Authority under agreement number 59809. We also thank Dr. Ellen Burkhard for helpful discussions. Dr. Pierce acknowledges funding from NSF (AGS-1559607) and NOAA (NA17OAR430001).

\section{SUPPLEMENTARY MATERIAL}

Supplementary data associated with this article can be found in the online version at https://doi.org/10.4209/aaqr.2 020.05 .0268

\section{REFERENCES}

Akimoto, H., Hoshino, M., Inoue, G., Sakamaki, F., Washida, N., and Okuda, M. (1979). Design and characterization of the evacuable and bakable photochemical smog chamber. Environ. Sci. Technol. 13: 471-475. https://doi.org/10.1021/es60152a014

Anisimova, L., Hopke, P.K., and Terry, J. (2001). Two channel vapor nucleation in the vicinity of the triple point. J. Chem. Phys. 114: 9852-9855. https://doi.org/10.1063/ 1.1372759

Bertrand, A., Stefenelli, G., Jen, C.N., Pieber, S.M., Bruns, E.A., Temime-Roussel, B., Slowik, J.G., Goldstein, A.H., El Haddad, I., Baltensperger, U., Prévôt, A.S.H., Wortham, H. and Marchand, N. (2018a). Evolution of the chemical fingerprint of biomass burning organic aerosol during aging. Atmos. Chem. Phys. 5194: 7607-7624. https://doi.org/10.5194/acp-18-7607-2018

Bertrand, A., Stefenelli, G., Pieber, S.M., Bruns, E.A., Temime-Roussel, B., Slowik, J.G., Wortham, H., Prévôt, A.S.H., El Haddad, I. and Marchand, N. (2018b). Influence of the vapor wall loss on the degradation rate 
constants in chamber experiments of levoglucosan and other biomass burning markers. Atmos. Chem. Phys. 5194: 10915-10930. https://doi.org/10.5194/acp-18-10915-2018

Bian, Q., May, A.A., Kreidenweis, S.M. and Pierce, J.R. (2015). Investigation of particle and vapor wall-loss effects on controlled wood-smoke smog-chamber experiments. Atmos. Chem. Phys. 15: 11027-11045. https://doi.org/10. 5194/acp-15-11027-2015

Booth, A.M., Montague, W.J., Barley, M.H., Topping, D.O., McFiggans, G., Garforth, A. and Percival, C.J. (2011). Solid state and sub-cooled liquid vapour pressures of cyclic aliphatic dicarboxylic acids. Atmos. Chem. Phys. 11: 655-665. https://doi.org/10.5194/acp-11-655-2011

Bufalini, J.J., Walter, T.A. and Bufalini, M.M. (1977). Contamination effects on ozone formation in smog chambers. Environ. Sci. Technol. 11: 1181-1185. https://doi.org/10.1021/es60136a009

Donahue, N.M., Robinson, A.L., Stanier, C.O. and Pandis, S.N. (2006). Coupled partitioning, dilution, and chemical aging of semivolatile organics. Environ. Sci. Technol. 40: 2635-2643. https://doi.org/10.1021/es052297c

Finlayson-Pitts, B.J. and Pitts, J.N. (1986). Atmospheric chemistry: Fundamentals and experimental techniques. Wiley, New York.

Grieshop, A.P., Donahue, N.M. and Robinson, A.L. (2007). Is the gas-particle partitioning in alpha-pinene secondary organic aerosol reversible? Geophys. Res. Lett. 34: 1-5. https://doi.org/10.1029/2007GL029987

Grosjean, D. (1985). Wall loss of gaseous pollutants in outdoor teflon chambers. Environ. Sci. Technol. 79: 1059-1065. https://doi.org/10.1021/es00141a006

Huang, Y., Zhao, R., Charan, S.M., Kenseth, C.M., Zhang, X. and Seinfeld, J.H. (2018). Unified Theory of vapor-wall mass transport in teflon-walled environmental chambers. Environ. Sci. Technol. 52: 2134-2142. https://doi.org/10. 1021/acs.est.7b05575

Isaacman-Vanwertz, G., Massoli, P., O’Brien, R., Lim, C., Franklin, J.P., Moss, J.A., Hunter, J.F., Nowak, J.B., Canagaratna, M.R., Misztal, P.K., Arata, C., Roscioli, J.R., Herndon, S.T., Onasch, T.B., Lambe, A.T., Jayne, J.T., Su, L., Knopf, D.A., Goldstein, A.H., Worsnop, D.R. and Kroll, J.H. (2018). Chemical evolution of atmospheric organic carbon over multiple generations of oxidation. Nat. Chem. 10: 462-468. https://doi.org/10.1038/s41557018-0002-2

Krechmer, J.E., Pagonis, D., Ziemann, P.J. and Jimenez, J.L. (2016). Quantification of gas-wall partitioning in Teflon environmental chambers using rapid bursts of low-volatility oxidized species generated in-situ. Environ. Sci. Technol. 50: 5757-5765. https://doi.org/10.1021/acs.est.6b00606

Krechmer, J.E., Day, D.A. and Jimenez, J.L. (2020). Always Lost but never forgotten: Gas-phase wall losses are important in all teflon environmental chambers. Environ. Sci. Technol. 54: 12890-12897. https://doi.org/10.1021/a cs.est.0c03381

Kristensen, K., Jensen, L.. N., Glasius, M., Bilde, M., and Bilde M. (2017). The effect of sub-zero temperature on the formation and composition of secondary organic aerosol from ozonolysis of alpha-pinene. Environ. Sci.
Process. Impacts 19: 1220-1234. https://doi.org/10.1039/ C7EM00231A

Kroll, J.H., Chan, A.W.H., Ng, N.L., Flagan, R.C. and Seinfeld, J.H. (2007). Reactions of semivolatile organics and their effects on secondary organic aerosol formation. Environ. Sci. Technol. 4: 3545-3550. https://doi.org/10.1 021/Es062059x

Kuwata, M., Shao, W., Lebouteiller, R. and Martin, S.T. (2013). Classifying organic materials by oxygen-tocarbon elemental ratio to predict the activation regime of Cloud Condensation Nuclei (CCN). Atmos. Chem. Phys. 13: 5309-5324. https://doi.org/10.5194/acp-13-5309-2013

La, Y.S., Camredon, M., Ziemann, P.J., Valorso, R., Matsunaga, A., Lannuque, V., Lee-Taylor, J., Hodzic, A., Madronich, S. and Aumont, B. (2016). Impact of chamber wall loss of gaseous organic compounds on secondary organic aerosol formation: Explicit modeling of SOA formation from alkane and alkene oxidation. Atmos. Chem. Phys. 16: 1417-1431. https://doi.org/10.5194/acp16-1417-2016

Matsunaga, A. and Ziemann, P.J. (2010). Gas-wall partitioning of organic compounds in a teflon film chamber and potential effects on reaction product and aerosol yield measurements. Aerosol Sci. Technol. 4: 881-892. https://doi.org/10.1080/02786826.2010.501044 May, A.A., Saleh, R., Hennigan, C.J., Donahue, N.M. and Robinson, A.L. (2012). Volatility of organic molecular markers used for source apportionment analysis: measurements and implications for atmospheric lifetime. Environ. Sci. Technol. 46: 12435-12444. https://doi.org/ 10.1021/es302276t

McMurry, P.H. and Grosjean, D. (1985). Gas and aerosol wall losses in Teflon film smog chambers. Environ. Sci. Technol. 19: 1176-82. https://doi.org/10.1021/es00142a006

McVay, R.C., Cappa, C.D. and Seinfeld, J.H. (2014). Vaporwall deposition in chambers: Theoretical considerations. Environ. Sci. Technol. 48: 10251-10258. https://doi.org/ 10.1021/es502170j

Nah, T., McVay, R.C., Zhang, X., Boyd, C.M., Seinfeld, J.H. and $\mathrm{Ng}$, N.L. (2016). Influence of seed aerosol surface area and oxidation rate on vapor wall deposition and SOA mass yields: A case study with $\alpha$-pinene ozonolysis. Atmos. Chem. Phys. 16: 9361-9379. https://doi.org/10.5194/acp-16-9361-2016

Nah, T., McVay, R.C., Pierce, J.R., Seinfeld, J.H. and Ng, N.L. (2017). Constraining uncertainties in particle walldeposition correction during SOA formation in chamber experiments. Atmos. Chem. Phys. 17: 2297-2310. https://doi.org/10.5194/acp-17-2297-2017

Oja, V. and Suuberg, E.M. (1999). Vapor pressures and enthalpies of sublimation of d-glucose, d-xylose, cellobiose, and levoglucosan. J. Chem. Eng. Data 44: 26-29. https://doi.org/10.1021/je980119b

Pathak, R.K., Stanier, C.O., Donahue, N.M. and Pandis, S.N. (2007). Ozonolysis of $\alpha$-pinene at atmospherically relevant concentrations: Temperature dependence of aerosol mass fractions (yields). J. Geophys. Res. 112: D03201. https://doi.org/10.1029/2006JD007436

Pierce, J.R., Engelhart, G.J., Hildebrandt, L., Weitkamp, E.A., 
Pathak, R.K., Donahue, N.M., Robinson, A.L., Adams, P.J. and Pandis, S.N. (2008). Constraining particle evolution from wall losses, coagulation, and condensationevaporation in smog-chamber experiments: Optimal estimation based on size distribution measurements. Aerosol Sci. Technol. 42: 1001-1015. https://doi.org/10.1 080/02786820802389251

Pratap, V., Bian, Q., Kiran, S.A., Hopke, P.K., Pierce, J.R. and Nakao, S. (2019). Investigation of levoglucosan decay in wood smoke smog-chamber experiments: The importance of aerosol loading, temperature, and vapor wall losses in interpreting results. Atmos. Environ. 199: 224 232. https://doi.org/10.1016/j.atmosenv.2018.11.020

Riipinen, I., Pierce, J.R., Donahue, N.M. and Pandis, S.N. (2010). Equilibration time scales of organic aerosol inside thermodenuders: Evaporation kinetics versus thermodynamics. Atmos. Environ. 44: 597-607. https://doi.org/10.1016/j.atmosenv.2009.11.022

Roldin, P., Eriksson, A. C., Nordin, E. Z., Hermansson, E., Mogensen, D., Rusanen, A., Boy, M., Swietlicki, E., Svenningsson, B., Zelenyuk, A., and Pagels, J. (2014). Modelling non-equilibrium secondary organic aerosol formation and evaporation with the aerosol dynamics, gas- and particle-phase chemistry kinetic multilayer model ADCHAM. Atmos. Chem. Phys. 14: 7953-7993. https://doi.org/10.5194/acp-14-7953-2014

Sato, K., Fujitani, Y., Inomata, S., Morino, Y., Tanabe, K., Ramasamy, S., Hikida, T., Shimono, A., Takami, A., Fushimi, A., Kondo, Y., Imamura, T., Tanimoto, H. and Sugata, S. (2018). Studying volatility from composition, dilution, and heating measurements of secondary organic aerosols formed during alpha-pinene ozonolysis. Atmos. Chem. Phys. 18: 5455-5466. https://doi.org/10.5194/acp18-5455-2018

Shah, V., Jaeglé, L., Jimenez, J.L., Schroder, J.C., CampuzanoJost, P., Campos, T.L., Reeves, J.M., Stell, M., Brown, S.S., Lee, B.H., Lopez-Hilfiker, F.D. and Thornton, J.A. (2019). Widespread pollution from secondary sources of organic aerosols during winter in the northeastern United States. Geophys. Res. Lett. 46: 2974-2983. https://doi.org/ 10.1029/2018GL081530

Taira, M. and Kanda, Y. (1990). Continuous generation system for low-concentration gaseous nitrous acid. Anal. Chem. 633: 630-633. https://doi.org/10.1021/ac00205a018

Takekawa, H., Minoura, H. and Yamazaki, S. (2003). Temperature dependence of secondary organic aerosol formation by photo-oxidation of hydrocarbons. Atmos.
Environ. 37: 3413-3424. https://doi.org/10.1016/S13522310(03)00359-5

Trump, E.R., Epstein, S.A., Riipinen, I. and Donahue, N.M. (2016). Wall effects in smog chamber experiments: A model study. Aerosol Sci. Technol. 50: 1180-1200. https://doi.org/10.1080/02786826.2016.1232858

Vaden, T.D., Imre, D., Beránek, J., Shrivastava, M. and Zelenyuk, A. (2011). Evaporation kinetics and phase of laboratory and ambient secondary organic aerosol. Proc. Natl. Acad. Sci. U.S.A. 108: 2190-2195. https://doi.org/ 10.1073/pnas. 1013391108

Warren, B., Austin, R.L. and Cocker, D.R. (2009). Temperature dependence of secondary organic aerosol. Atmos. Environ. 43: 3548-3555. https://doi.org/10.1016/ j.atmosenv.2009.04.011

Ye, P., Ding, X., Hakala, J., Hofbauer, V., Robinson, E.S. and Donahue, N.M. (2016). Vapor wall loss of semivolatile organic compounds in a Teflon chamber. Aerosol Sci. Technol. 50: 822-834. https://doi.org/10.1080/02786 826.2016.1195905

Yeh, G.K. and Ziemann, P.J. (2015). Gas-wall partitioning of oxygenated organic compounds: Measurements, structure-activity relationships, and correlation with gas chromatographic retention factor. Aerosol Sci. Technol. 6826: 727-738. https://doi.org/10.1080/02786826.2015.1 068427

Yli-Juuti, T., Pajunoja, A., Tikkanen, O., Buchholz, A., Faiola, C., Väisänen, O., Hao, L., Kari, E., Peräkylä, O., Garmash, O., Shiraiwa, M., Ehn, M., Lehtinen, K. and Virtanen, A. (2017). Factors controlling the evaporation of secondary organic aerosol from $\alpha$-pinene ozonolysis. Geophys. Res. Lett. 44: 2562-2570. https://doi.org/10.100 2/2016GL072364

Zhang, X., Schwantes, R.H., McVay, R.C., Lignell, H., Coggon, M.M., Flagan, R.C. and Seinfeld, J.H. (2015). Vapor wall deposition in Teflon chambers. Atmos. Chem. Phys. 15: 4197-4214. https://doi.org/10.5194/acp-15-41972015

Ziemann, P.J. and Atkinson, R. (2012). Kinetics, products, and mechanisms of secondary organic aerosol formation. Chem. Soc. Rev. 41: 6582. https://doi.org/10.1039/C2CS 35122F

Received for review, May 28, 2020

Revised, August 12, 2020

Accepted, September 29, 2020 